\title{
Sport as an Instrument for People Development and Peace Promotion
}

\section{Andrea Brunelli and Paolo Parisi}

In the last decade a growing number of initiatives using sport as tool to stimulate personal and social improvements have been implemented in developing countries. This new sector of sport utilization which has received a lot of attention and recognition by the international community is defined as the Sport for Development and Peace (SDP) movement.

In this review, the basic features of the SDP phenomenon, the steps towards its official recognition, and the basic characteristics of the projects delivered will be outlined.

Moreover, the usefulness of measuring the impact of the activities implemented and the expected contribution of the academic community to this new and stimulating reality will be further discussed in the conclusions.

\section{Introduction}

$\mathbf{P}$ articipation in sport and more generally physical activity has been widely recognized to be an important lifestyle habit that can help people of different ages, genders and cultures to maintain a longer, healthier and therefore better, quality of life (US Surgeon General, 1996).

Benefits deriving from exercise mostly involve the prevention of numerous lifestyle-related diseases, namely, chronic or non-communicable diseases, which nowadays affect a vast number of persons both in developed and developing countries (WHO, 2003; WHO, 2004).

Sport also provides psychosocial benefits by stimulating social interactions (Coakley, 1993), reducing tendency to depression (Kubesch et al., 2003) and improving cognitive vitality (Kramer et al., 1999), concepts that are perfectly in line with the World Health Organization (WHO) definition of 'Health' described as 'a state of complete physical, mental and social well-being and not merely the absence of disease or infirmity' (WHO, 2006).

Paolo Parisi,, Department of Health Sciences, University of Rome "Foro Italico", Rome Italy; Andrea Brunelli; Department of Health Sciences, University of Rome "Foro Italico", Rome Italy,

Despite this role of sport participation as a behavior that can stimulate an holistic health and well being of the people, a recognition of the potentialities of sport as an instrument to promote also development and peace objectives all around the world has been recently recognized (United Nations, 2003a).

This new sector of sport utilization, which in the last decade has seen an incredible growth of dedicated projects in all corners of the planet, has increased in its own recognition and status and is internationally defined as the Sport for Development and Peace (SDP) movement (Kidd, 2008).

SDP can be described as the utilization of sport as a tool to foster personal and social improvements of those people and communities most in need of development (Houlihan, 2002); more specifically, it refers to the intentional use of sport, physical activity and play to achieve selected development and peace objectives including the Millennium Development Goals (MDGs) (United Nations, 2003a), a set of 8 main development objectives that the international community is committed to achieve by 2015 (United Nations, 2000). It is 
well accepted that sport alone cannot enable to achieve all the MDGs, nevertheless it is considered as a possible valuable component to address each of these development challenges (SDPIWG, 2008).

\section{International recognition}

In recent years, the international community has increasingly recognized and focused attention and resources on the potential of sport for the promotion of development and peace around the world.

Despite only recently the United Nations (UN) have officially emphasized 'the power of sport as tool to promote peace, health education and economic objectives' (United Nations, 2003b), the frame toward a formal recognition of sport as a fundamental right for all was outlined much earlier.

Already in 1978 the UN Educational Scientific and Cultural Organization (UNESCO) in the 'International Charter of Physical Education and Sport' described sport and physical education participation as 'a fundamental right for all' underlining that 'access to physical education and sport should be assured and guaranteed for all human beings ' (UNESCO, 1978).

Shortly after, the "Convention on the Elimination of All Forms of Discrimination against Women', ratified in 1979, recognized the right for all the women to equally participate in sport activities as men are used to, stating that 'on the basis of equality of men and women must be ensured with opportunities to participate actively in sports and physical education' (United Nations, 1981).

Another important formal step in this direction was the ratification, in 1989, of the 'Convention on the Rights of the Child', which in art. 31 affirms 'the right of the children to rest and leisure, to engage in play and recreational activities appropriate to their age' (UNICEF, 1989).
But it was only from 2001 that the United Nations started to formally recognize that apart from being a human right, sport could be also used to achieve selected development objectives such as those concerning poverty reduction, universal education, promotion of gender equality, environmental sustainability and HIV/AIDS prevention (United Nations, 2003a; Beutler, 2008) .

In order to define how sport could be employed, a specific task force including different UN agencies was created and a first official report entitled 'Sport for Development and Peace: Towards Achieving the Millennium Development Goals' was published in 2003. In this landmark publication, it is concluded that "...well-designed sport-based initiatives are practical and cost-effective tools to achieve objectives in development and peace. Sport is a powerful vehicle that should be increasingly considered by the UN as complementary to existing activities" (United Nations, 2003a).

Since then, numerous initiatives have been taken to coordinate and strengthen the role of sport as an instrument for achieving the goals and objectives of the United Nations. The clearest expression of this attention and belief on the sport's potentialities was the proclamation of 2005 as the 'International Year of Sport and Physical Education', adopted by the UN General Assembly in November 2003 (United Nations, 2003b), that stimulated a better global understanding of the value of sport and physical education for human development and generated a more systematic use of sport in development programs (Beutler, 2008).

The UN Resolution 58/5 entitled "Sport as a Means to Promote Education, Health, Development and Peace" was the final step of this process of formal recognition of the SDP movement. This resolution calls on governments, sports organizations, UN agencies, development organizations, sports associations and the academic community as well to cooperate in order to promote greater awareness and action to foster peace and accelerate the attainment of MDGs through sport-based initiatives. Specifically, the 
academic sector is encouraged to promote research and expertise in the field in order to enable ongoing training, capacity building and education for the teachers, coaches and community leaders involved in SDP programs (United Nations, 2010).

\section{Definition of Sport}

Despite the definition of 'Sport' may vary a lot in different cultures and countries, in this particular development context it includes a wide typology of activities that are suitable to people of all ages and abilities and that are practiced with the intention to maximize the benefits of the positive values of sport.

In 2003, the UN Inter-Agency Task Force on Sport for Development and Peace defined sport, for the purposes of development, as "all forms of physical activity that contribute to physical fitness, mental well-being and social interaction, such as play, recreation, organized or competitive sport, and indigenous sports and games." (United Nations, 2003a). This definition has been accepted by the stakeholders involved within the SDP movement and is therefore the definition that we will adopt in this review as well.

More specifically, play, especially among younger people, includes any physical activity that is participatory and fun. It is normally unstructured and free from adult direction. Recreation is more organized than play and generally entails physically active leisure activities. Sport is even more organized and involves rules or customs and sometimes competition. Importantly, play, physical recreation and sport are all freely chosen activities undertaken for pleasure (United Nations, 2003a). Moreover, the concept of 'sport for all' is central within the SDP thematic and strong emphasis is indeed placed on facilitating participation and inclusion for all groups of the targeted communities regardless of their gender, age, ability or race (United Nations, 2010).

\section{The contribution of Sport}

SDP projects can be very effective when utilized either at local, regional or global scale, and can make an important contribution to increase the quality of life of the people, especially of the most disadvantage ones (SAD, 2005).

Despite sport can carry a lot of positive values, its effectiveness in improving the life conditions of the people depends by many factors, such as the quality of the projects that are implemented and, most important, the educators/coaches who run the everyday activities; when sport educators are motivated, well trained and represent positive role models for the youths, they facilitate the transfer of the skills learned during the activities into the everyday life of those they are training and provide a protected space where children, adolescents and young adults can learn and practice social skills (Biddle, 2006).

Differently from a normal sport and recreational activity, a SDP project has the unique characteristic of carrying additional values and intended educational outcomes, where the activities are expressly and formally used as tools and resources to achieve additional objectives and not only for the own sake and pleasure of participation.

SDP projects can be implemented in many different places and situations: from short-term emergency humanitarian aid activities (like for example after a natural disaster or a conflict), where sport and play activities can provide psychosocial support to children (Henley, 2005), or in long-term development projects (like for example in a refugee camp or within an assistance program for street children) (SDPIWG, 2007a). Well structured sport initiatives can foster changes in the behavior of the people, helping them to become aware about how to engage in healthy life choices and how to prevent infections such as malaria or sexually transmitted diseases (SDPIWG, 2007a; Delva, 2010). Participation in sport is often used as a powerful tool of inclusion for persons with disabilities. Disabled people who actively practice sport activities feel less discriminated, more confident in their abilities and more 
involved within their communities (SDPIWG, 2008). Sport as gate opener to increase the physical, emotional and social life of disabled people is very important in developing countries, considering that among the 600 million people living with disability, $80 \%$ are currently living in these nations (World Bank, 2004), where proper assistance is often lacking and discrimination is very high.

It is also well accepted that sport projects can empower women by helping them to become more aware of their rights and their possible contribution within society. Girls who have access to sport develop new skills, can find support from other female participants and can experience freedom of expression and movement. The protective environment created by properly structured physical activities can stimulate girls' education, increase their selfesteem and enable them to make correct choices about their lives (Meier, 2008) .

Moreover, some authors (Schulenkorf, 2010) suggested that inter-community sport events have the capacity to function as active and exciting vehicles for stimulating positive social changes and reconciliation among different ethnic communities.

Despite sport can also trigger violent and antisocial behaviors among people (Sack et al., 2000), it is also accepted that it can be seen as a potentially effective instrument to foster peace and reconciliation objectives because many of the principal values intrinsic in sport, such as fair play, sense of responsibility, tolerance, cooperation, mutual understanding and sharing, are compatible with the principles that contribute to a culture based on peaceful values. Sport represents a communication platform, where people from different sides can find space for dialogue, individuals can re-connect to communities (like programs for re-integration of child soldiers) and in general can help to build or re-build social relationship in a non-violent and constructive manner. There are now several sport projects active in post-conflict areas (like for example in the Balkans, Ruanda, Palestine, Democratic Republic of Congo) and there is a certain evidence that when these project are properly structured and supervised and based on positive values, they can be very effective in restoring dialogue and peace between peoples and communities that were previously in conflict (Gasser, P. \& Levinsen, 2004).

Non-governmental organizations (NGOs) were among the first to recognize and harness the sport's development and peace potential. Some of them focus on the promotion of a specific sport (soccer, basketball, volleyball are the most used) and integrate it with a particular delivering methodology, characteristic of each NGO, aimed to improve the knowledge, health and overall quality of life of their participants; other realities instead utilized a wide variety of sports, play and physical activities, and tailor them according to the target of the participants, the issues they want to deal with and the community where the project is implemented. Moreover while some of these organizations are primarily and specifically focused on sport, an increasing number are more generalist in their approach and see sport just as an additional valuable tool to be used in combination with other initiatives in order to strengthen their development and peace efforts.

In this regard, an operative distinction has been made between the so defined 'Sport-Plus' approach in which the sport intervention is seen as the primary agent that is supposed to lead benefits to the participants, and the 'Plus-Sport' approach which instead involves activities that are integrated into a broader development program (SAD, 2005); in this vision, it is not only the value of sport itself that is supposed to bring about positive changes, but sport is seen as an instrument that, in parallel with other assistance initiatives, can contribute to the development objectives.

In fact, while an organization can run its own project's activities in an independent way, most of the cases the sport-related initiatives represent just a part of a greater intervention which involves different actions and different stakeholders, each one holding different responsibilities. In a very recent publication (Comic Relief, 2007) it is concluded that 'it is not sport itself that brings about change, instead 
it is the set of processes and relationships used to deliver and support the sporting intervention that are fundamental to achieving development goals'; while in another, well conducted review (SDPIWG, 2007b) it is specifically reported that, apart from physical health benefits, interventions that focus only on sport participation are unlikely to produce long-term beneficial effects and they suggested that in order 'to fully utilize the development potential of sport, it needs to be integrated in the existing development and peace efforts'.

It is now well recognize that this cooperative and integrated action, using sport as a tool within a more articulated development intervention, is the most effective and longlasting type of approach.

\section{Basic features of an SDP project}

Within the sport for development framework, sport is considered as a tool to achieve other, more complex, developmental objectives that can assist the empowerment of the people involved in the programs. Therefore, it is necessary to determine already during the 'planning phase' which are the values and the development objectives to be achieved with the project activities.

Generally, it is expected that any SDP project bases its efforts towards the valorization and reinforcement of all the positive values of sport (Sportsmanship) (NSD, 2010). The type of activities implemented should not aim at objectives and ambitions connected to elitesport or sport professionalism but rather to maximize the inclusive and enjoyable participation of the highest number of people (NSD, 2010; Hayhurst, 2010).

Since SDP projects can be implemented almost everywhere in the world, in different cultural, social and environmental contexts and each project may have different issues to tackle, it is very challenging to define clear guidelines or the specific operations that need to characterize such type of intervention.
However, considering the experience of the last 10 years of projects' delivering and evaluation (conducted by different NGOs, UN agencies, sport federations, etc.), it's now commonly accepted the following principles that need to characterize any SDP initiative from its very beginning:

First of all, any SDP project needs to be as much inclusive as possible. It means that the highest number of people within the selected community, especially those who have more difficulties to have access, need to be involved; particular emphasis needs to be focused on differently able people, women and cultural minorities. Barriers to participation must be identified and addressed and activities should be adapted accordingly to guarantee the maximal access for all.

Physical and emotional safety for all participants must be constantly guaranteed. It is necessary to protect all employees, participants/athletes when they are on the project sites or doing any activity related to the project. Particular attention must be focused on the safety of girls in general, before, during and after the activities, because they are the most vulnerable group (NSD, 2010).

All the activities need to be implemented by motivated and expert coaches and teachers who not only need to be trained on the specific technical sport skills, but also they must know how to foster a transfer of the skills learned during sport to the everyday life situations of the participants. All sport educators must possess appropriate qualifications, attitudes and experience to plan and effectively implement projects. They must receive appropriate training, supervision, management and support to ensure effective and competent work within the project (NSD, 2010).

The planning, implementation and follow-up of the activities need to be based on the 'bottom-up model'. The best community development relies on the expressed needs and available resources of the local population, which need to be defined during an a consultative planning 
process between the NGOs and the recipient communities (Kidd, 2008).

A good SDP project involves different stakeholders that are capable to work in a coordinated and non-conflictual manner. This approach based on the intentional, noncompetitive sharing of resources is normally more effective (Comic Relief, 2007).

An SDP project needs to remain active on a long-term basis; changes in the behaviors and attitudes of the persons, and the consequent impact at social level, require years before they can happen and be consolidated.

The positive or negative (expected or unexpected) changes in the people, due to the intervention, need to be measured. The impact of the sport activities needs to be monitored and evaluated with specific tools which should be selected and used from the beginning of the project. In this regard, the contribution of the academic sector, including, more specifically the collaboration between sport sciences experts with scholars from the development field need to be encouraged (Comic Relief, 2007).

When programming an SDP intervention, emphasis must be given to its sustainability, which is the ability to maintain a project active long after the international donors and the developmental organizations have gone. This is one of the main reasons why much attention, empowerment and role in decision-making should be given to the local people affected by the projects activities.

\section{Evidence of effectiveness: the role of the academic community}

Considering the very high and constantly growing number of projects around the world that are intentionally using sport as a tool for improving the well being of the people (over 400 sport-for- development NGOs have been established in recent years) (Hayhurst, 2010) and considering all the supportive claims that have been made in this regard, also by authoritative agencies (United Nations 2003a, 2003b; SDPIWG, 2008) and journals (Koss \& Alexandrova, 2005), surprisingly, the production of appropriate scientific evidence is still very limited (Kidd, 2008; Levermore \& Beacom, 2009).

Despite the usefulness of sport as a tool for development has been reported in a number of articles, studies and reports, most of these analyses generally come from the monitoring and evaluation data collected directly by the delivering sport NGOs, which rarely have resources to invest on the expertise and impartiality of external evaluators. The consequence is that the results reported are highly descriptive and often very positive, but contain only little evidence in support of these claims. Data are collected using a wide number of different instruments (registers for attendance, questionnaires, interviews, diaries etc.) which are often created 'ad hoc' for each project location; the consequence is therefore the difficulty to transfer similar analyses to projects placed in other cultural or geographical contexts.

The study design utilized is also often inappropriate (few pre-post intervention analyses, control groups are often lacking and, due to the only recent appearance of SDP projects, longitudinal evidence does not exist). Moreover , many of the psychological constructs used to measure changes in the attitudes and behaviors of the people or changes in their perceptions, are measured with psychological tests (such as the Rosenberg Selfesteem scale or the Likert scale for the measurement of self-efficacy) that have been developed and validated for people living in Western societies and therefore may not be totally reliable and reproducible for people from emarginated communities or disabled (Hatcher, 2007; Davis et al., 2009).

The 'gold standard' for scientific evaluation is the peer-review process that leads to the publication of the different studies in 'refereed journals'. However, Levermore \& Beacom (2007) have identified that among 70.000 abstract appeared on peer-review development literature, only 12 contained the word 'sport'. 
They and other scholars underlined the importance of increasing the quality and quantity of theory-based primary research within the sport for development sector.

From then (2007) until now, only few more peer-reviewed articles have appeared on this topic. For example, a search on the most popular database (PubMed) for scientific articles including the words 'Sport' and 'Peace' still yields no results; moreover, at the largest European meeting of sport science, the 15th Congress of the European College of Sport Science held in 2010 in Antalya, among 1.300 abstracts of poster and oral presentations presented, no one contained the word 'Peace' or 'Reconciliation' and only one contained the word 'Fair-Play' (ECSS, 2010). Research on this topic is therefore warranted not only to find ways to improve the quality of the projects and their implementing methodologies but also to open a novel, stimulating and prolific window of research within the sport science sector.

Targett and Wolff (2010) have recently underlined the importance of the creation of a specific 'field of study' within the SDP framework, defined as a 'a branch of knowledge that is taught and researched at University level , recognized by scientific journals, and recognized by departments and faculties to which their practitioners belong' (Clarke et al. 1987, cited in Matthews \& Wolff).

Moreover, taking the model of sport management recognition as academic field, the authors suggested that, in order to contribute to a further growth of the SDP movement, the academic sector needs to advocate in order to: initiate specific degree programs and produce scholarly journals on the thematic. Also the establishment of professional associations for SDP practitioners can contribute to a further recognition of this professional sector.

Nevertheless, in the latest years, some attempts have been made in order collect and review the available evidence; however these efforts have produced only weak and somewhat contrasting results which have not yet been published on peer-reviewed journals.
For example, while the review of the Sport for Development and Peace International Working Group (SDPIWG, 2007) summarizes that 'there are some key findings, which demonstrate that, under the right conditions, sport has the potential to contribute to development and social issues', the COMIC Relief's review (Comic Relief, 2007) is more critical regarding the available evidence, describing it as too descriptive, mostly focused on youth, and carrying only weak evidence in support of the claims that are made. Interestingly, the authors also underlined that most of the production has come through sport scientists mainly from the West/ North societies and not from those based in the recipients countries (Comic Relief, 2007). Even in this analysis' process, a bottom-up approach, defined 'participatory monitoring and evaluation' with a greater involvement of the direct beneficiaries in the collection and interpretation of the data would be warranted, as their active involvement and contribution would help to build their capacity as decision-makers.

Although the two reviews were conducted in the same period, differences in the conclusions might be explained with the fact that different studies were included. Moreover, without speculating on the impartiality of the authors, it is also worth noting that the two organizations that commissioned the reviews (SDPIWG and Comic Relief) have different roles in relation with the SDP sector and therefore might have been interested in searching for different type of information within the available literature. In fact, while SDPIWG is a policy initiative aiming to develop recommendations for governments to incorporate sport as a tool for development into their national and international programs and strategies (SDPIWG, 2006), Comic Relief is a grant provider which believes in the power of sport as a tool, but is also keen to understand how the programs have brought about lasting changes in the lives of those directly benefiting from them (Comic Relief, 2009).

In this general effort to collect evidence about the effectiveness of SDP projects it is worth to mention the recent analysis conducted by prof. Coalter (Coalter, 2010), one of the leading 
scholars in this field. His study aimed to evaluate how 'sport contributes to the personal development and well-being of disadvantaged children and young people'. The research was undertaken in collaboration with six sport-fordevelopment organizations operating in different continents (Africa and Asia) and social situations (Street children, internally displaced people and others). Also the age and gender of the target people were different (boys and girls, aged 14 and over). The working hypothesis was that the programs could contribute to the personal development of the participants by increasing their self-efficacy (i.e., the individual's belief in her/ his ability to achieve a particular outcome or to address difficult issues), which in turn would lead to increased self-esteem (i.e., the individual's sense of self worth).

As expected, the results indicated that the majority of respondents increased their evaluations for perceived self-efficacy (between 88 and 93\%) and self-esteem (79-93\%) with a general tendency for those with the weakest or lower self-evaluations to increase more.

A part from the apparent positive benefits of the six sport interventions, it was also reported that the subjects had a relatively normal evaluation of themselves also before they started the activities. Accordingly, it was suggested that the general assumption that deprived communities produce deficient individuals (deficit - model) should be reevaluated.

\section{Conclusion}

At this point, considering the evidence from this study and the conflicting data of previous reviews, it should be questioned whether it is worth to continue to invest resources in measuring such psychological constructs (especially self-efficacy and self-esteem) as major indicators of the impact made.

Probably, a more biologically oriented type of analysis conducted on aware volunteers, in an ethical, approved and non-invasive manner (for example using saliva samples to measure stress hormones before and after an SDP intervention), combined with already available tools (questionnaires, focus group discussions, interviews), could be an additional innovative instrument to gather more evidence about the real contribution of sport initiatives towards the achievement of the MDGs.

However this intriguing type of interaction between psycho-social and biological factors could represent only a partial level of investigation of a multifaceted reality and it should never be neglected more attention to the socio-political dynamics (within and between communities and nations) which remain the most important yet the most difficult to measure type of contribution that sport can make to foster positive social changes at global level.

In conclusion, SDP movement is a young, global and complex phenomenon which is growing and evolving very fast. The quality of the projects implemented is increasing also because organizations, and more in general SDP practitioners, are more aware of why and how to measure and evaluate the consequences (i.e. outcomes) of the activities delivered.

Therefore, decision-makers of the sport-science sector should devote more interest to the area and have the courage to invest resources into grassroots research. The more we move away from the laboratory setting, the lower the quality and reproducibility of scientific evidence; however, it is also true that as we come closer to the people in the field, a more environmentrelated evidence is also attainable, and can be transferred to different projects locations. The hope is that the amount of knowledge that will be collected over the next years will not remain just in the academic journals but will find a direct and useful application in the field. A great contribution to this process of dissemination can be offered by a recently established international organization called 'International Sport for Development and Peace Association (ISDPA)', which brings together scholars, educators, practitioners and policy makers with the intention to support, coordinate and disseminate quality academic and field-based research that may further the professional 
development of the SDP field (ISDPA, 2010). As we better understand how (directly or indirectly) sport can contribute to achieve developmental goals, more persons will truly benefit from the different interventions, keeping in mind that the long-lasting improvement of the quality of life of the people participating in the sport projects must remain the driving motivation and force for all those who will become involved in this fascinating reality.

Acknowledgments: . Andrea Brunelli is a PhD student in the European Doctoral Program in Health and Physical Activity.

\section{References}

Beutler, I. (2008). Sport serving development and peace: Achieving the goals of the United Nations through sport. Sport in Society. 11: 359-369.

Biddle, S. (2006). Defining and measuring indicators of psycho-social wellbeing in youth sport and physical activity. from Auweele, Y.V., Malcolm, C. and Meulders, B. in Sport and Development.

Coakley, J. (1993). Sport and Socialization. Exerc Sport Sci Review. 21: 169-200.

Coalter, F. (2010). Sport-for-development impact study. A research initiative funded by Comic Relief and UK Sport and managed by International Development through Sport. University of Stirling.

Comic Relief (2007). A literature review of sport and development.

Comic Relief (2009). International Sport for Change Programme Strategy. 2010-2012.

Davis, C., Kellett, S. and Beail, N. (2009). Utility of the Rosenberg self esteem scale. Am. J. Intellect. Dev. Disabil. 114: 172-178.

Delva, W. et al. (2010). HIV prevention through sport: the case of the Mathare Youth Sport Association in Kenya. AIDS Care. 22: 1012-20.
ECSS 15th Congress of European College of Sport Sciences (2010). Book of Abstracts. ISBN 978-605-61427-0-3.

Gasser, P. \& Levinsen, A. (2004). Breaking Post-War Ice: Open Fun Football Schools in Bosnia and Herzegovina. Sport in Society. 7: 457-472.

Hatcher, J. (2007). The state of measurement of self-esteem of African American women. J. Transcult. Nurs. 18: 224-232.

Hayhurst, L. \& Frisby, W. (2010). Inevitable tensions: Swiss and Canadian sport for development NGO perspectives on partnerships with high performance sport. European Sport Management Quarterly. 1:75-96.

Henley, R. (2005). Helping Children Overcome Disaster Trauma Through Post-Emergency Psychosocial Sports Programs. Swiss Academy for Development. Biel.

Houlihan, B., \& White, A. (2002). The Politics of sports development: development of sport or development through sport? London: Routledge.

International Sport for Development and Peace Association (ISDPA). Information retrieved on $12 / 2010$ from the International SDP platform, www.sportanddev.org.

Kidd, B. (2008). A new social movement: Sport for development and peace. Sport in Society. 11: $370-380$.

Koss, J.O. \& Alexandrova, A. (2005). Essay: HIV/AIDS prevention and peace through sport. Lancet. 366: S3-4.

Kramer, A.E., Hahn, S., Cohen, N.J. et al. (1999). Aging, fitness and neurocognitive function. Nature. 400: 418-419.

Kubesch, S., Breschneider, V., Freudenmann, R., Weidenhammer, et al. (2003). Aerobic endurance exercise improves executive functions in depressed patients. Journal of Clinical Psychiatry. 64: 1005 - 1012.

Levermore, R. and Beacom A. (2009). Sport and Development: Mapping the Field. In R. Levermore and A. Beacom (Eds.), Sport and 
International Development

Houndsmills: Palgrave Macmillan.

Meier, M. (2008) Gender, Equity, Sport and

Development. Swiss Academy for

Development.

Network for Sport and Development (NSD) (2010). The Code of Conduct for sports and development organizations.

Sack, A.L. and Suster, Z. (2000). Soccer and Croatian nationalism: A prelude to war. Journal of Sport and Social Issues. 24: 305-320.

Schulenkorf, N. (2010). Sport events and ethnic reconciliation: Attempting to create social change between Sinhalese, Tamil and Muslim sportspeople in war-torn Sri Lanka. International Review for the Sociology of Sport. 45: 273.

SDPIWG (2006). Sport for Development and Peace: From Practice to Policy. Preliminary report of the Sport for Development and Peace International Working Group.

SDPIWG (2007a). Right To Play publication. From the Field: Sport for Development and Peace in Action.

SDPIWG (2007b). University of Toronto. Literature reviews on sport for development and peace.

SDPIWG (2008). Right to Play publication. Harnessing the power of sport development and peace: recommendations to governments.

Swiss Agency for Development and Cooperation (2005). Sport for Development and Peace.

Targett, M. and Wolff, E. (2010). Sport for development and peace: a perspective on defining the field. Brown University. Global Conversation. Online Resource retrieved on 12/2010 from www.globalconversation.org.
United Nations (1978). UNESCO. International Charter of Physical Education and Sport.

United Nations (1981). Convention on the Elimination of all Forms of Discrimination Against Women.

United Nations (1989). UNICEF. Convention on the Rights of the Child.

United Nations (2000). United Nations Millennium Declaration. A/Res/55/2.

United Nations. Inter-Agency Task Force on Sport for Development and Peace (2003a). Sport for Development and Peace: Towards Achieving the Millennium Development Goals. Geneva.

United Nations (2003b). Sport as a Means to Promote Education, Health, Development and Peace. Resolution 58/5, adopted by the General Assembly, New York.

United Nations (2010). Sport as a Means to Promote Education, Health, Development and Peace. Resolution 65/4, adopted by the General Assembly, New York.

US Surgeon General. US Department of Health and Human Services (1996). Physical Activity and Health: A Report of the Surgeon General, Atlanta.

World Bank (2004). Disability \& HIV/AIDS, World Bank.

World Health Organization (2003). Health and Development Through Physical Activity and Sport, Geneva.

World Health Organization (2005). Facing the Facts \#1: Chronic Diseases and Their Common Risk Factor, Geneva.

World Health Organization (2006). Constitution of the World Health Organization. 45th ed. 